\title{
A BALANCED FOUR-POINT LINKAGE EXPERIMENT FOR LINKAGE GROUP XIII OF THE HOUSE MOUSE
}

\author{
P. A. PARSONS \\ Department of Genetics, University of Cambridge
}

Received 9.v.57

\section{INTRODUCTION}

LINKAGE group XIII in the house mouse was established by Fisher in $195^{\circ}$ when he reported recombination between polydactyly $(p y)$ and leaden $(l n)$.

Polydactylous mice have appeared in numerous stocks for some ycars. As an inherited cntity, polydactyly has been reported by Murray (1932), Strong (1934), Fortuyn (1939), and finally by Holt (1945). It was, however, of very poor manifestation, and was not usable as a genctic factor until Holt (1945) had selected for good manifestation after outcrossing. Leaden, a recessive factor, arose in the same inbred chocolate-brown stock in which Murray found polydactylous mice (Murray, I933).

The next factor, now known to belong to this linkage group, that occurred, was splotch $(S p)$, which is a dominant and was reported by Russell (1947). In I949 Strong and Hollander reported looptail $(L p)$, which is a badly manifesting dominant of poor viability, and is therefore difficult to work with. At this stage, Fisher reported his p. - -ln linkage, and this was quickly followed by Dickie and Woolley (I950) who reported a new recessive factor fuzzy ( $f z$ ) linked to $\ln$ with a recombination value of $40.9 \pm 3.7$ for female heterozygous parents, and $4 \mathrm{I} \cdot 5 \pm 4 \cdot 5$ for males. They also reported a linkage between fi and $S p$ of $4^{1 \cdot} \cdot 3 \pm 5^{\cdot 2}$.

Fisher set out the position for the py-ln linkage fully in 1953 . He obtained a recombination value of $40 \cdot 3 \pm \mathrm{I} \cdot 77$ for females, and $23 \cdot 0 \pm 2 \cdot 00$ for males, which is a striking sex difference. Data for the linkage of $L . p, I n, S p$, and $f z$, appeared in 1954 (Snell, Dickie et al.) :

TABLE ,

Linkage of $\mathrm{Lp}, \ln , \mathrm{Sp}, \mathrm{fz}$

\begin{tabular}{|c|c|c|c|c|c|}
\hline & $L f$ & $\ln$ & & $s p$ & $f z$ \\
\hline $\begin{array}{c}\text { Hetcrozygous ô } \\
\text { " }\end{array}$ & $\begin{array}{l}35 \cdot 1 \\
3^{8 \cdot 1}\end{array}$ & & $\begin{array}{l}5 \cdot 8 \\
8 \cdot 5\end{array}$ & & $\begin{array}{l}3 \mathrm{I} \cdot 6 \\
39^{\cdot} \cdot 6\end{array}$ \\
\hline
\end{tabular}

These data show a sex difference but not of the magnitude found by Fisher.

From these preliminary tests, it was evident that the markers in this linkage group served to map a greater map distance than is 
available in any other linkage group in the house mouse. An accurate knowledge of recombination and interference along this chromosome would help to verify or modify recent theories of genetical recombination developed mainly by Owen. For this reason, Fisher set up matings designed to map this chromosome as accurately as possible using the four markers $p y, l n, S p$, and $f z$. The factor $p y$ is thought to be situated very close to $L p$, and in the stocks in this Department $p y$ is the easier factor to work with. In this paper four-point data for the long segment $p y$-ln- $S p$ - $f z$ will be analysed and the results discussed. They are derived from the material built up by Fisher over the last five years, and have not yet been reported.

\section{THE FACTORS INVOLVED}

A brief description of the factors $p y, \ln , S p$, and $f z$, will be given here with particular reference to any difficulties encountered while working with them.

\subsection{Polydactyly}

The polydactylous mice in this Department originated in one of Fisher's inbred lines, the TS line, at the Galton Laboratory in January $194^{2}$, from which a polydactyl line was set up. Prior to this occurrence, polydactyl mice appeared in a lightheaded (le te) line, but test matings were shortlived and no polydactyl mice were obtained (Holt, 1945).

Polydactylous mice are readily observable at birth. With very few exceptions, polydactyly has been confined to the back feet, affecting either or both feet. When one foot is affected, it is more commonly the right foot (Holt, 1945). This was confirmed by Engel (1956).

The condition is very variable in expression, and all stages have been recorded from a slight abnormality where the first toe appears shorter and thicker than normal, to a severe form where there are seven complete toes. When both feet are affected, one foot is often affected differently from the other.

Holt (1945) has given the early history of polydactyly in considerable detail and showed that it is a recessive incompletely penetrant factor of highly variable expression. Inbreeding and outcrossing to several lines which had never shown polydactyly improved its manifestation considerably. Further selection by Fisher (1953) established within a year a stock in which it is invariably manifest. It appears that suppressors of unequal intensity inhibit $p y$ manifestation, one of which is in the Vth chromosome probably between agouti and pallid (Fisher, 1950). By selection, these suppressors have been removed.

In the linkage experiment to be analysed, homozygous polydactyly is manifest mainly as bilateral polydactylism. Of the animals affected on one foot, approximately two-thirds will be shown to be homozygous and one-third heterozygous. It is conceivable that further selection could make the factor still less recessive. This would be in agreement with Holt's (1945) suggestion that py may have been a dominant initially, but by natural selection acting through modifiers, the heterozygote has tended to resemble the advantageous homozygote as suggested by Fisher (1928).

\subsection{Leaden}

Leaden, first reported by Murray (1933), is a completely recessive factor with Ioo per cent. manifestation in the homozygous state. It is a dilution factor, and the homozygotes do not appear to be less viable than the heterozygotes. Classification can be made at about six days. 


\subsection{Splotch}

Splotch, $S p$, is a dominant factor manifest by white spotting on the belly and occasionally on the back. The feet have white socks, and the tail may be partially white. It interacts with other spotting factors, e.g. piebald $(s)$ and dominant pied $(W)$ which can make classification difficult in some stocks. Classification can be made at about eight days.

\subsection{Fuzzy}

Fuzzy is a completely recessive factor with perfect manifestation. The hair on fuzzy mice is thinner and faintly wavy and the vibrissæ also are wavy. Fuzzy mice appear to be weaker in the litter initially but eventually grow to normal size. This is verified by a deficiency of homozygotes in the records.

\subsection{Conclusions}

This survey of the markers in linkage group XIII reveals some difficulties. Leaden is an excellent factor to work with, having perfect viability and manifestation. Fuzzy mice are of lowered viability in the litter. Splotch viability is normal but there is a slight danger of misclassification. Polydactyly has manifestation troubles but the $p y$ manifestation was relatively constant in the period when the data to be analysed in this cxperiment were collected.

\section{DESIGN OF EXPERIMENT}

There are eight possible quadruple heterozygotes for four linked markers, and eight possible modes of gamete formation. The eight heterozygotes were made up and backcrossed to a triply recessive stock of $p y f z \ln$ mice of Ioo per cent. $p y$ manifestation. The data from such a series of eight crosses can be arranged as an $8 \times 8$ Latin square in which the columns represent the eight modes of gamete formation, and the rows the eight quadruply heterozygous genotypes (table 2). If we let the three segments between the four markers $f z-S p$ - $\ln$ - $p y$ be (I), (2), and (3), respectively, then the eight modes of gamete formation can be designated by (0), (1), (2), (3), (12), (23), and (123), such that (o) represents no recombination, (I) represents recombination in segment ( $\mathrm{r}$ ), and so on.

The letters A-H correspond to the eight pairs of complementary genotypes

$\begin{array}{lll}\mathrm{A} & S p & f z \ln p y \\ \mathrm{~B} & f z S p & \ln p y \\ \mathrm{C} & S p \ln p y & f z \\ \mathrm{D} & S p p y & f z \ln \\ \mathrm{E} & f z S p \ln p y & + \\ \mathrm{F} & f z S p p y & \ln \\ \mathrm{G} & S p \ln & f z p y \\ \mathrm{H} & f z S p \ln & p y\end{array}$

The eight possible heterozygotes were made up and some effort was made to collect approximately equal data from each heterozygote 
(table 3) so as to ensure balance. Balance is achieved when there are data in coupling and repulsion for each possible pair of factors. In a four-point test, sets of only four heterozygotes which are balanced can be selected. In this experiment, however, there are data for the eight possible heterozygotes so ensuring balance.

TABLE 2

$8 \times 8$ Latin square

\begin{tabular}{|c|c|c|c|c|c|c|c|c|}
\hline \multirow{2}{*}{$\begin{array}{l}\text { Parental } \\
\text { genotypes }\end{array}$} & \multicolumn{8}{|c|}{ Modes of gamete formation } \\
\hline & (o) & (1) & (2) & (3) & (12) & (13) & (23) & (123) \\
\hline 1. $\frac{f z+\ln p y}{+S p++}$ & A & $\mathbf{B}$ & $\mathrm{G}$ & D & $\mathrm{E}$ & F & G & $\mathbf{H}$ \\
\hline 2. $\frac{++\ln p y}{f z S p++}$ & B & A & $E$ & $\mathbf{F}$ & $\mathrm{C}$ & D & $\mathbf{H}$ & G \\
\hline 3. $\frac{+S p \ln p y}{f z+++}$ & C & $\mathrm{E}$ & A & G & B & $\mathbf{H}$ & D & $\mathbf{F}$ \\
\hline 4. $\frac{f z+\ln +}{+S p+p y}$ & $\mathbf{D}$ & $\mathbf{F}$ & G & $A$ & $\mathbf{H}$ & B & $\mathrm{C}$ & E \\
\hline 5. $\frac{f z S p \ln p y}{++++}$ & $\mathbf{E}$ & C & $\mathrm{B}$ & $\mathbf{H}$ & A & G & $\mathbf{F}$ & D \\
\hline 6. $\frac{f z S p+p y}{++\ln +}$ & $\mathbf{F}$ & $\mathbf{D}$ & $\mathbf{H}$ & B & G & A & $\mathrm{E}$ & $\mathrm{C}$ \\
\hline 7. $\frac{+S p \ln +}{f z++p y}$ & G & $\mathbf{H}$ & $\mathbf{D}$ & C & F & $\mathrm{E}$ & A & B \\
\hline 8. $\frac{f z S p \ln +}{+++p y}$ & $\mathbf{H}$ & G & $\mathbf{F}$ & $E$ & D & $C^{\prime}$ & B & A \\
\hline
\end{tabular}

\section{ANALYSIS OF THE DATA}

The data for the female and male heterozygotes are summarised in table 3. The modes of gamete formation are shown along the top of the table, and the eight parental genotypes which can be seen from table 2 are shown along the side. Each pair of complementary genotypes A-H is split into its components, with the totals shown, these corresponding to the letters of the $8 \times 8$ Latin square. In the table the top figure of a complementary pair represents $S p$ mice and hence from table 2 their exact genotypes can be found. For each mode of gamete formation there are two columns, the first giving the female data, and the second the male data.

Before proceeding to the actual analysis, some comments will be made on the selection of data which are compiled in the $8 \times 8$ Latin squares.

The greatest difficulty encountered in these data was the variable manifestation of $p y$. In the early stages, when the manifestation of 


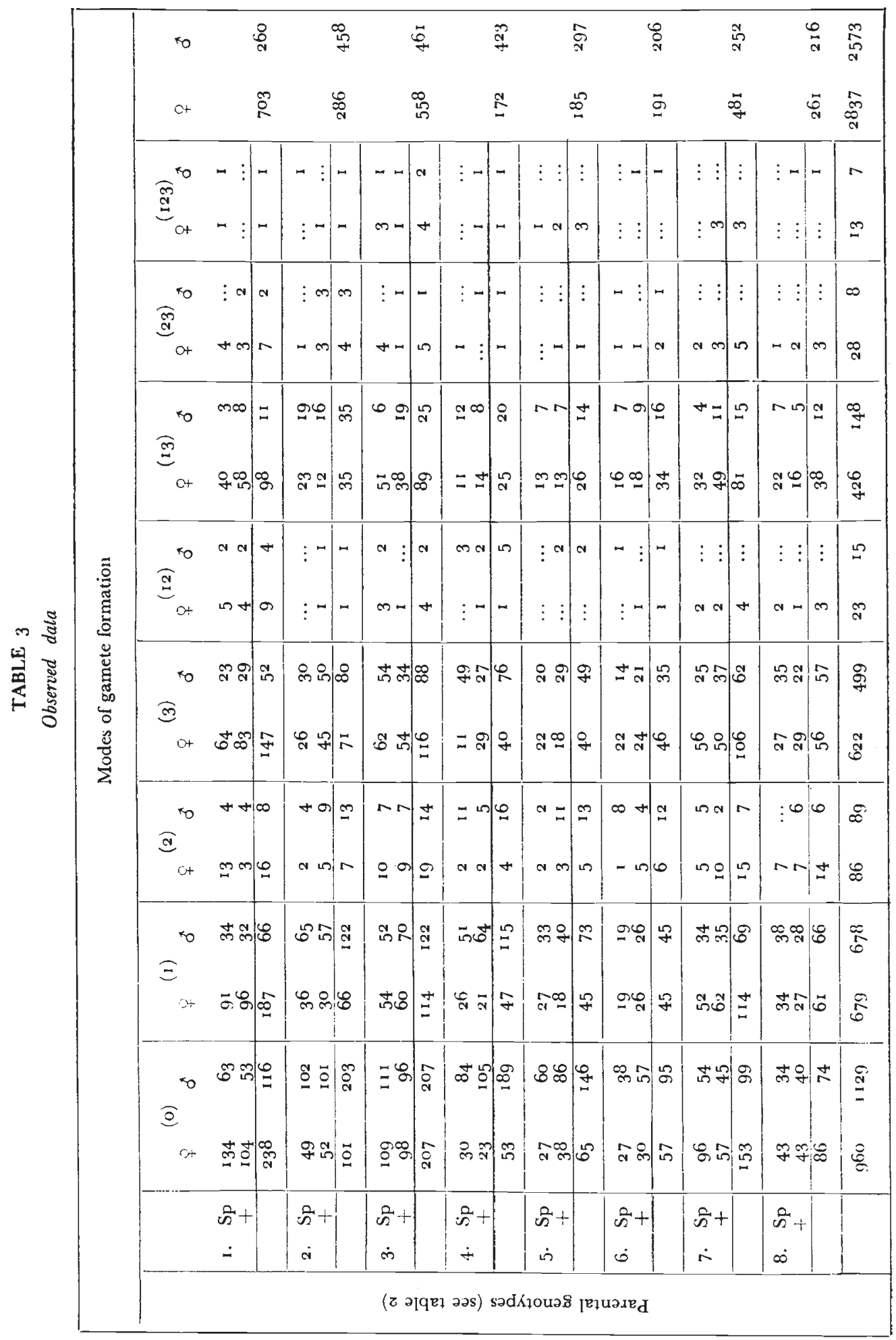


py was being built up, or when a new factor was introduced to the stock, e.g. $f z$ and $S p$, the $p y$ manifestation was greatly upset and varied considerably between matings. The main problem in the data presented here is, however, the identity of animals polydactylous on one foot. Animals polydactylous on both feet were almost invariably

TABLE +

Distribution of polydactylous mice

\begin{tabular}{|c|c|c|}
\hline & Female & Male \\
\hline \multirow{4}{*}{$\begin{array}{l}\text { Polydactylous on both feet } \\
\text { Polydactylous on neither foot } \\
\text { Polydactylous on one foot }\end{array}$} & 1371 & 1193 \\
\hline & 1466 & 1380 \\
\hline & 345 & 374 \\
\hline & 3182 & 2947 \\
\hline
\end{tabular}

py py, and those normal on both feet $p y+$, but breeding tests showed that animals polydactylous on one foot could be either $p y p y$ or $p y+$.

In the discussion on viability it will be shown that animals manifesting $p y$ are no less viable than those not manifesting $p$ \%. If it is assumed that any disturbance in the $p y p y:+p y$ ratio, which is expected to be I : I in a backcross linkage experiment, is due to manifestation, some estimate of the proportions of animals polydactylous on one foot which are homozygous and heterozygous can be made. In table 4 ,

TABLE 5

Distribution of mice polydactylous on one foot

\begin{tabular}{|c|c|c|}
\hline & Female & Male \\
\hline$p y p y$ & 63.77 per cent. & $75 \cdot 00$ per cent. \\
$+p y$ & $3^{6 \cdot 23,}$ & $25 \cdot 00$, \\
\hline
\end{tabular}

the data are split into three classes-(i) non-polydactylous, (ii) polydactylous on one hind-foot, and (iii) polydactylous on both hind feet. Data from female quadruple heterozygotes are separated from those from male heterozygotes.

The animals which show polydactyly on one foot are distributed among the other two classes such that the ratio $p y p y:+p y$ is $\mathrm{I}: \mathrm{I}$. It is seen (table 5) that approximately two-thirds of this doubtful class is py py.

When this doubtiul class was disregarded, the segregations in many matings became much more normal. It was therefore thought best, for the purposes of analysis, to disregard this class entirely. Before doing this, however, the distribution of this doubtful class anongst the eight modes of gamete formation was ascertained, and found to 
be incompatible with the remainder of the data. Equally noticeable were the numerous animals appearing in the rare cross-over classes.

The other difficulty in some of the data was $S p$ classification, but selection of data for good $S p$ manifestation should remove any source of error. For most of the data, however, this difficulty did not arise, as selection and familiarity with the gene virtually eliminated any possible misclassification. As in the case of animals polydactylous on one foot, misclassification of $S p$ was often obvious by virtue of excessive $S p$ animals in the rare cross-over classes.

\subsection{Preliminary analysis}

Various preliminary tests are necessary before recombination can be safely estimated by the simple addition of the column totals in the $8 \times 8$ Latin squares. These tests may be classified into two types. Firstly, various tests may be done to test whether the data are heterogeneous. If so, the reliability of any estimates of recombination will be doubtful. Secondly, there are tests to detect viability and manifestation effects. If only one gene is of lowered viability, recombination can be estimated by adding the column totals. In this case, each cell of the $8 \times 8$ square will be affected equally by the viability effect. However, if two or more genes are of lowered viability, there will be genotypic viability differences and recombination must be estimated using a computation to remove such differences. The procedure for such computations has been developed by Fisher and set out by Fisher (1949) and Parsons (I957a) for three-point data. The former is a good first approximation, and the latter yields a solution to any desired degree of accuracy by an iterative process.

As a preliminary test of heterogeneity, a general $\chi^{2}$ test which tests the agreement of observations and proportionate expectations based upon column and row totals may be calculated. For this test, columns (2), (12), (23), and (123) are neglected as the entries in these columns are very small. This leaves a $4 \times 8$ table. For the female data $\chi^{2}$ was $16 \cdot 5^{8}$ for $2 \mathrm{I}$ degrees of freedom such that $0.7<\mathrm{P}<0.8$ and for the male data $\chi_{2 \mathrm{~T}}^{2}=30 \cdot 36(0 \cdot 05<\mathrm{P}<0 \cdot \mathrm{I})$. Neither of these tests reveal significant heterogeneity. Heterogeneity can occur as a result of poor data, or variable recombination according to the parental heterozygote, or finally as a result of differential genotypic viabilities. It may be concluded that such effects, if present, are probably negligible.

It is to be expected that the members of a pair of complementary gcnotypes will be unequal because of viability and manifestation disturbance. However, if the data are reliable, such deviations from the expected I : i ratio for no disturbance within a complementary pair should not be heterogeneous amongst the eight possible parental quadruple heterozygotes. Furthermore, there should be no differences in the magnitude of the disturbance encountered according to the sex of the quadruply heterozygous parent. 
TABLE $6 z$

Heterogeneity tests for members of complementary pairs

\begin{tabular}{|c|c|c|c|c|c|c|c|c|}
\hline \multicolumn{9}{|c|}{ Data arranged for testing } \\
\hline Genotypes & (o) & (I) & (3) & (I3) & 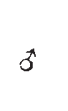 & 우 & Total & $\begin{array}{l}\text { Total includ- } \\
\text { ing }(2),(12), \\
(23),(123)\end{array}$ \\
\hline A ${ }_{f z} \ln p y$ & $\begin{array}{l}197 \\
157\end{array}$ & $\begin{array}{r}\mathrm{IOI}_{1} \\
87\end{array}$ & $\begin{array}{l}6 a \\
5^{6}\end{array}$ & $\begin{array}{l}23 \\
27\end{array}$ & $\begin{array}{l}184 \\
146\end{array}$ & $\begin{array}{l}197 \\
181\end{array}$ & $\begin{array}{l}381 \\
327\end{array}$ & $\begin{array}{l}400 \\
349\end{array}$ \\
\hline Totals & 354 & $x 88$ & I 6 & $5^{\circ}$ & 330 & 378 & 708 & 749 \\
\hline B $\underset{\ln p y}{S p} f z$ & $\begin{array}{l}\text { I } 51 \\
\text { I } 53 \\
\end{array}$ & $\begin{array}{l}125 \\
128 \\
\end{array}$ & $\begin{array}{l}36 \\
45 \\
\end{array}$ & $\begin{array}{l}23 \\
22 \\
\end{array}$ & $\begin{array}{l}162 \\
162 \\
\end{array}$ & $\begin{array}{l}173 \\
186 \\
\end{array}$ & $\begin{array}{l}335 \\
348 \\
\end{array}$ & $\begin{array}{l}345 \\
368 \\
\end{array}$ \\
\hline Totals & 304 & 253 & 81 & 45 & 324 & 359 & 683 & 713 \\
\hline C $S_{f z} p p y \ln$ & $\begin{array}{l}220 \\
194\end{array}$ & $\begin{array}{l}60 \\
5^{8}\end{array}$ & $\begin{array}{l}81 \\
87\end{array}$ & $\begin{array}{l}29 \\
21\end{array}$ & $\begin{array}{l}\times 76 \\
178\end{array}$ & $\begin{array}{l}214 \\
182\end{array}$ & $\begin{array}{l}390 \\
360\end{array}$ & $\begin{array}{l}408 \\
371\end{array}$ \\
\hline Totals & $4^{14}$ & 118 & I68 & $5^{\circ}$ & 354 & $39^{6}$ & $75^{\circ}$ & 779 \\
\hline D $S p p y$ & $\begin{array}{l}114 \\
128 \\
\end{array}$ & $\begin{array}{l}38 \\
5^{2} \\
\end{array}$ & $\begin{array}{r}87 \\
102 \\
\end{array}$ & $\begin{array}{l}4^{2} \\
3^{8} \\
\end{array}$ & $\begin{array}{l}145 \\
176\end{array}$ & $\begin{array}{l}\text { I } 36 \\
\text { I } 44\end{array}$ & $\begin{array}{l}28 \mathrm{I} \\
320\end{array}$ & $\begin{array}{l}298 \\
337 \\
\end{array}$ \\
\hline Totals & $24^{2}$ & 90 & 189 & 80 & $3^{2 \mathrm{I}}$ & 280 & 601 & 635 \\
\hline$\underset{+}{\mathrm{E} f z} \operatorname{spln} p y$ & $\begin{array}{r}87 \\
124 \\
\end{array}$ & $\begin{array}{l}106 \\
\text { 1 } 30 \\
\end{array}$ & $\begin{array}{l}62 \\
5^{1} \\
\end{array}$ & $\begin{array}{l}36 \\
60 \\
\end{array}$ & $\begin{array}{l}151 \\
189 \\
\end{array}$ & $\begin{array}{l}140 \\
176 \\
\end{array}$ & $\begin{array}{l}291 \\
365\end{array}$ & $\begin{array}{l}306 \\
3^{888} \\
\end{array}$ \\
\hline Totals & $2 \mathrm{II}$ & 236 & II 3 & $9^{6}$ & $34^{\circ}$ & $3^{16}$ & 656 & 694 \\
\hline F $\underset{l n}{f z} S p p y$ & $\begin{array}{l}65 \\
87 \\
\end{array}$ & $\begin{array}{l}77 \\
85 \\
\end{array}$ & $\begin{array}{l}56 \\
95 \\
\end{array}$ & $\begin{array}{l}43 \\
66\end{array}$ & $\begin{array}{r}122 \\
179 \\
\end{array}$ & $\begin{array}{r}119 \\
154 \\
\end{array}$ & $\begin{array}{l}241 \\
333 \\
\end{array}$ & $\begin{array}{l}254 \\
35 \mathrm{I} \\
\end{array}$ \\
\hline Totals & 152 & 162 & ${ }^{1} 5^{I}$ & rog & 301 & 273 & 574 & 605 \\
\hline $\begin{array}{r}\text { G } S p l n \\
f z p y\end{array}$ & $\begin{array}{l}150 \\
102 \\
\end{array}$ & $\begin{array}{l}72 \\
55\end{array}$ & $\begin{array}{r}\mathrm{I} 16 \\
88\end{array}$ & $\begin{array}{l}20 \\
20\end{array}$ & $\begin{array}{l}\text { I } 53 \\
\text { I } 14\end{array}$ & $\begin{array}{l}205 \\
151\end{array}$ & $\begin{array}{l}358 \\
265\end{array}$ & $\begin{array}{l}377 \\
279\end{array}$ \\
\hline Totals & $25^{2}$ & 127 & 204 & 40 & 267 & $35^{6}$ & 623 & 656 \\
\hline $\mathrm{H} \underset{p y}{S p} f z \ln$ & $\begin{array}{l}77 \\
83 \\
\end{array}$ & $\begin{array}{l}86 \\
97 \\
\end{array}$ & $\begin{array}{l}4^{2} \\
47 \\
\end{array}$ & $\begin{array}{l}57 \\
57 \\
\end{array}$ & $\begin{array}{r}94 \\
123 \\
\end{array}$ & $\begin{array}{l}168 \\
16 \mathrm{r} \\
\end{array}$ & $\begin{array}{l}262 \\
284 \\
\end{array}$ & $\begin{array}{l}277 \\
302 \\
\end{array}$ \\
\hline Totals & 160 & 183 & 89 & 114 & 217 & 329 & 546 & 579 \\
\hline
\end{tabular}

The procedure for carrying out such tests can be illustrated by considering the first complementary pair in table 6 , namely $S p$ and $f z \ln p y$. The observed number of $S p$ mice is 400 and of $f z \ln p y 349$. If there is no disturbance, equality would be expected. Assuming a 1 : I ratio, a $\chi_{\mathrm{I}}^{2}$ testing the agreement of observed and expected 
was $3.47(0.05<\mathrm{P}<0 . \mathrm{I})$ (table $6 b)$, which is suggestive of some disturbance.

In the heterogeneity test to find out whether the $S p: f z \ln p y$ ratio varies in the data, columns (2), (12), (23) and (123) of the $8 \times 8$ Latin squares are neglected, as the data in these columns are often inadequate to give, an accurate $\chi^{2}$ test. For the four remaining columns a $\chi_{3}^{2}$ test may be carried out to test the agreement of observed and expected frequencies calculated on the basis of row and column totals. This test gave $\chi_{3}^{2}=\mathrm{I} \cdot 9 \mathrm{I}(0.5<\mathrm{P}<0.7)$ which is not significant.

Finally, it is of interest to find out whether each sex behaves similarly in regard to these deviations. The total mice in each sex is given for each genotype in a $2 \times 2$ table (table $6 a$ ). Proportionality

TABLE $6 b$

\begin{tabular}{|c|c|c|c|c|c|c|}
\hline \multicolumn{7}{|c|}{$\chi^{2}$ tests from data in table $6 a$} \\
\hline $\begin{array}{c}\text { Geno- } \\
\text { types }\end{array}$ & $\begin{array}{l}\chi^{2} \mathrm{c} \\
\text { for sex } \\
\text { differ- } \\
\text { ences }\end{array}$ & $\mathbf{P}$ & $\begin{array}{l}\chi^{2}{ }_{1} \text { for } \\
\text { over-all } \\
\text { viability }\end{array}$ & $P$ & $\begin{array}{c}\chi^{2}{ }_{3} \text { for } \\
\text { heterogeneity } \\
\text { between members } \\
\text { of a complementary } \\
\text { pair }\end{array}$ & $\mathbf{P}$ \\
\hline $\begin{array}{l}\text { A } \\
\text { B } \\
\text { C } \\
\text { D } \\
\text { E } \\
\text { F } \\
\text { G } \\
\text { H }\end{array}$ & $\begin{array}{l}0 \cdot 80 \\
0 \cdot 16 \\
1 \cdot 23 \\
0 \cdot 56 \\
0 \cdot 003 \\
0 \cdot 43 \\
0 \cdot 0001 \\
2 \cdot 84\end{array}$ & $\begin{aligned} 0.3 & <\mathbf{P}<0.5 \\
0.5 & <\mathbf{P}<0.7 \\
0.2 & <\mathbf{P}<0.3 \\
0.3 & <\mathbf{P}<0.5 \\
\mathbf{P} & >0.9 \\
0.5 & <\mathbf{P}<0.7 \\
\mathbf{P} & >0.9 \\
0.05 & <\mathbf{P}<0.1\end{aligned}$ & $\begin{array}{r}3 \cdot 47 \\
0.74 \\
1 \cdot 76 \\
2 \cdot 40 \\
9 \cdot 69 \\
15.55 \\
14.64 \\
1.08\end{array}$ & $\begin{array}{c}0.05<\mathrm{P}<0.1 \\
0.3<\mathrm{P}<0.5 \\
0.1<\mathrm{P}<0.2 \\
0.1<\mathrm{P}<0.2 \\
\mathrm{P}<0.01 \\
\mathrm{P}<0.001 \\
\mathrm{P}<0.00 \mathrm{I} \\
0.2<\mathrm{P}<0.3\end{array}$ & $\begin{array}{l}1 \cdot 91 \\
0.82 \\
1.96 \\
1 \cdot 86 \\
7 \cdot 75 \\
3 \cdot 86 \\
1 \cdot 41 \\
0 \cdot 28\end{array}$ & $\begin{aligned} 0.5 & <\mathrm{P}<0.7 \\
0.8 & <\mathrm{P}<0.9 \\
0.5 & <\mathrm{P}<0.7 \\
0.5 & <\mathrm{P}<0.7 \\
0.05 & <\mathrm{P}<0.1 \\
0.2 & <\mathrm{P}<0.3 \\
0.7 & <\mathrm{P}<0.8 \\
\mathbf{P} & >0.9\end{aligned}$ \\
\hline
\end{tabular}

of rows and columns is tested with a contingency $\chi_{\mathrm{r}}^{2}$ applying Yates' correction for continuity. For complementary pair $A, \chi_{\mathrm{r}}^{2}=0 \cdot 80$ $(0.3<\mathrm{P}<0.5)$ which is clearly not significant.

These tests are applied to the remaining seven pairs of complementary genotypes in table 6 . In some cases there are very serious deviations from the I : I ratio expected from members of complementary pairs, but such deviations are maintained throughout the data as is shown by the non-significance of the heterogeneity tests involved. No significant sex difference is detected for any of the complementary pairs.

The conclusions that may be drawn from this test are (i) there are disturbances affecting the expected I : I ratio of members of complementary pairs, (ii) such disturbances are maintained throughout any complementary pair in which they may exist, and (iii) there is no detectable difference in behaviour between the sexes.

The result of this analysis brings us to the question of the nature of such disturbances, and more important, the question of their effect, if any, on the recombination values to be estimated. A preliminary and crude test may be done by examining single factor ratios obtained 
directly by addition from the observed progeny (table 7). Equality of these ratios is tested with a simple $\chi_{1}^{2}$.

TABLE 7

Single factor ratios

\begin{tabular}{|c|c|c|c|c|c|}
\hline Factor & & $f z$ & $s p$ & $\ln$ & $p y$ \\
\hline $\begin{array}{l}\text { Normals } \\
\text { Mutants }\end{array}$ & : & $\begin{array}{l}2892 \\
25^{18}\end{array}$ & $\begin{array}{l}2745 \\
2665\end{array}$ & $\begin{array}{l}2637 \\
2773\end{array}$ & $\begin{array}{l}2846 \\
2564\end{array}$ \\
\hline Total & . & $54^{10}$ & 5410 & $54^{10}$ & $54^{10}$ \\
\hline${\stackrel{\chi^{2}}{2}}^{2}$. & . & $\begin{array}{l}25 \cdot 86 \\
\mathbf{P}<0 \cdot 001\end{array}$ & $\begin{array}{c}\quad \cdot \cdot 18 \\
0.2<P<0.3\end{array}$ & $0.05<\frac{3 \cdot 4^{2}}{\mathrm{P}}<0.1$ & $\mathrm{P}<{ }^{14 \cdot 70}$ \\
\hline
\end{tabular}

From these totals it is obvious that there is, as expected, a deficiency of $f z$ and $p y$ mice.

The problem of polydactyly is more complex. It is known that there is a deficiency of polydactylous mice, by virtue of the discard of the doubtful animals which were polydactylous on one hind foot only. This, however, does not eliminate the possibility of a viability effect, although from the appearance of young polydactylous mice, this is unlikely. Polydactylous mice can be classified at birth and in this Department they are never left more than three days before initial classification. Full classification for all genes cannot be completed until the mice are eight to ten days old. Viability effects of polydactyly which may have occurred between initial recording and full classification, can be tested by noting the number of $p y$ mice and normal mice dying in that period out of a given total. For 2596 mice classified in such a manner, the following table is obtained.

TABLE 8

Viability of polydactyly

\begin{tabular}{|cc|c|c|c|}
\hline & & $\begin{array}{c}\text { Classified } \\
\text { at birth }\end{array}$ & $\begin{array}{c}\text { Died before full } \\
\text { classification }\end{array}$ & Total \\
\hline Polydactylous. &. & ${ }^{1} 174$ & 43 & 1217 \\
Non-polydactylous & $\cdot$ & ${ }^{1} 327$ & 52 & 1379 \\
\hline Total &. & 2501 & 95 & 2596 \\
\hline
\end{tabular}

The proporticnality of rows can be tested with a $\chi_{\mathrm{I}}^{2}$ applying Yates' correction for continuity. For this table $\chi_{\mathrm{r}}^{2}=0.05$ $(0.8<\mathrm{P}<0.9)$. Thus there is no detectable difference between the mortality of polydactylous and normal mice between initial recording 
and full classification. The deficiency of polydactylous mice compared with normals can therefore be assumed to be mainly an effect of poor manifestation.

An additional test can be done to test any possible interactions between the four factors. If we ignore $S p$ and $l n$, and consider $f z$ and $p y$, the eight pairs of complementary genotypes can be split into four pairs consisting of a $f z p y:++$ contrast, and a $f z+:+p y$ contrast :

\begin{tabular}{|c|c|c|c|c|c|c|c|}
\hline Genotype & ++ & $f z p y$ & Total & Genotype & $f z$ & $p y$ & Total \\
\hline $\begin{array}{l}A \\
E \\
F \\
G\end{array}$ & $\begin{array}{l}400 \\
388 \\
351 \\
377\end{array}$ & $\begin{array}{l}349 \\
306 \\
254 \\
279\end{array}$ & $\begin{array}{l}749 \\
694 \\
605 \\
656\end{array}$ & $\begin{array}{l}\text { B } \\
\text { C } \\
\text { D } \\
\mathrm{H}\end{array}$ & $\begin{array}{l}345 \\
371 \\
337 \\
277\end{array}$ & $\begin{array}{l}368 \\
408 \\
298 \\
3^{02}\end{array}$ & $\begin{array}{l}713 \\
779 \\
635 \\
579\end{array}$ \\
\hline Total & 1516 & $\begin{array}{l}1188 \\
\end{array}$ & 2704 & & 1330 & 1376 & 2706 \\
\hline
\end{tabular}

The ratio $++: f z p y$ is significantly different from the expected I : I ratio for no disturbance $\left(\chi_{\mathrm{r}}^{2}=14 \cdot 64, \mathrm{P}<\mathrm{O} \cdot 00 \mathrm{I}\right)$. However, a heterogeneity test on the four components of this contrast to ascertain whether the deviation is consistent throughout the data is not significant $\left(\chi_{3}^{2}=3.62,0.3<\mathrm{P}<0.5\right)$. In the case of the $f z+:+p y$ contrast, the over-all ratio is not significantly different from unity $\left(\chi_{\mathrm{r}}^{2}=0.78\right.$, $0.3<\mathrm{P}<0.5)$. The heterogeneity test on the four components of this contrast is also non-significant $\left(\chi_{3}^{2}=5 \cdot 19,0 \cdot \mathrm{I}<\mathrm{P}<0 \cdot 2\right)$. If the factors $S p$ or $\ln$ were affected by viability, or if there were any interactions, the above heterogeneity tests might have been significant.

This somewhat lengthy series of preliminary tests gives a lead to the method of computation to be used in the estimation of the recombination fractions. It has been shown that $f z$ is the only factor which is of reduced viability when homozygous, and that there are no interactions with the other factors. This viability effect is therefore equally distributed in each cell of the $8 \times 8$ tables, and in the estimation of recombination by simple addition of the column totals, the effect will cancel out.

Partial manifestation of polydactyly will bias the results if the effect is not estimated and removed. A relatively simple computation deals with this difficulty, and will be given in the next section.

In conclusion, these preliminary tests have shown that (i) the results are not heterogeneous, (ii) there is a simple viability effect due to $f z$, and (iii) there is a manifestation effect of $p y$. Hence, the use of a relatively simple computation to remove bias due to poor $p$, manifestation will provide accurate estimates of recombination without recourse to the difficult and lengthy computations of the type given by Fisher (1949) for the case where there is a significant genotypic differential viability effect. 


\subsection{Estimation of recombination}

The mode of computation to be used in a balanced linkage experiment when one of the factors is imperfectly penetrant has been set out by Parsons $(1957 b)$ for three-point data and extended briefly to four-point data.

Let the frequencies of the eight modes of gamete formation (o), (1), (2), (3), (12), (13), (23) and (123) be $p, q, r, s, t, u, v$ and $w$, respectively such that

$$
p+q+r+s+t+u+v+w=1
$$

and let $\lambda=$ misclassification of $p y$.

Admitting misclassification of $p y$, eight linear equations can be obtained from the $8 \times 8$ Latin square which will easily yield the eight modes of gamete formation :

$$
\begin{gathered}
p+\lambda(s-p)=\mathrm{P} \\
q+\lambda(u-q)=\mathrm{Q} \\
r+\lambda(v-r)=\mathrm{R} \\
s+\lambda(p-s)=\mathrm{S} \\
t+\lambda(w-t)=\mathrm{T} \\
u+\lambda(q-u)=\mathrm{U} \\
v+\lambda(r-v)=\mathrm{V} \\
w+\lambda(t-w)=\mathrm{W}
\end{gathered}
$$

In these equations $\mathrm{P}, \mathrm{Q}, \mathrm{R}, \mathrm{S}, \mathrm{T}, \mathrm{U}, \mathrm{V}$, and $\mathrm{W}$ are the observed column totals of the $8 \times 8$ Latin square. Taking the aboye equations in the pairs $(P, S),(Q, U),(R, V)$, and $(T, W)$, the eight modes of gamete formation may easily be estimated.

The misclassification $\lambda$ may be calculated using the method given by Parsons (1957 $b$ ) for three-point data.

Thus we sum the proportion of $p y$ in each of eight possible pairs of genotypes, one member of each pair being polydactylous and the other identical to the first but non-polydactylous. Hence it is required to find the sum of :

$$
\frac{\text { total observed } f z S p \ln p y \text { mice }}{\text { total observed }(f z S p \ln p y+f z S p \ln ) \text { mice }}+\ldots \text { to } 8 \text { terms }
$$

which is equal to $4(\mathrm{I}-\lambda)$. Each of the above ratios has a simple binomial variance and the variance of $\lambda$ is one-sixteenth of the sum of the variances of each of the eight ratios, the covariance term being zero as eight non-overlapping totals are being considered.

For the female data $\lambda=3 \cdot 8$ 1 $3 \pm 1 \cdot 876$ per cent., and for the male, $\lambda=6 \cdot 9 \mathrm{ro} \pm \mathrm{I} \cdot 959$ per cent.

In table 9 the six recombination values are given with standard errors.

These recombination values show a striking sex difference, the females almost invariably giving greater recombination values than the male, except over the entire segment $f z-p y$ where $49 \cdot 3^{2}$ per cent. 
recombination is obtained in the females and 49.44 per cent. in the males. The $p y-\ln$ value agrees with Fisher (1953), although the large difference between the sexes that he obtained is reduced a little. In the other long segment, $S p-f z$, the sex difference is significant, but not as striking as for the $p y$-ln segment. The figures obtained here agree reasonably with the figures of Snell, Dickie et al. (I954).

The $l n-S p$ values are smaller than those given by Snell, Dickie et al. (1954), and very much smaller than the first data given for this linkage by Ingalls (reported in Snell, Dickie et al.). In these first

TABLE 9

Recombination values

\begin{tabular}{|c|c|c|c|}
\hline \multirow{2}{*}{ Segment } & \multirow{2}{*}{$\begin{array}{c}\text { Modes of } \\
\text { gamete formation }\end{array}$} & \multicolumn{2}{|c|}{ Recombination values } \\
\hline & & Females & Males \\
\hline $\begin{array}{l}p y-\ln (3) \\
\ln -S p(2) \\
S p-f z(1) \\
p y-f z(123) \\
p y-S p(23) \\
\ln -f z \text { (12) }\end{array}$ & $\begin{array}{c}s+u+v+w \\
r+t+v+w \\
q+t+u+w \\
q+r+s+w \\
r+s+t+u \\
q+r+u+v\end{array}$ & $\begin{array}{r}37 \cdot 9 \pm 0 \cdot 98 \\
5 \cdot 3 \pm 0 \cdot 42 \\
40 \cdot 2 \pm 0 \cdot 92 \\
49 \cdot 3 \pm 0 \cdot 97 \\
40 \cdot 4 \pm 0 \cdot 97 \\
43 \cdot 0 \pm 0 \cdot 93\end{array}$ & $\begin{array}{r}23 \cdot 9 \pm \mathrm{r} \cdot 06 \\
4 \cdot 6 \pm 0 \cdot 4 \mathrm{r} \\
33 \cdot 0 \pm 0 \cdot 93 \\
49 \cdot 4 \pm \mathrm{r} \cdot 06 \\
27 \cdot 6 \pm \mathrm{r} \cdot 06 \\
35.9 \pm 0 \cdot 95\end{array}$ \\
\hline
\end{tabular}

data, $S p$ classification was complicated by piebald $(s)$ segregation and recombination values were $9 \cdot 8 \pm 7 \cdot 8$ for females, and $9 \cdot 7 \pm 4.5$ for males. Any misclassification would almost certainly give spuriously high values for a small segment. It seems probable that the figures reported here are nearer to the true values as very little $S p$ misclassification was detected.

However, the novel feature of these data is the equality of $p y-f z$ recombination values in both sexes when compared with the lower values obtained for males in the segments making up the $p y-f z$ segment.

\section{DISCUSSION}

\subsection{Interference}

A simple measure of interference is the Kosambi coefficient $\mathrm{K}$ (Owen, 1950). In a backcross experiment involving two segments $\mathrm{AB}$ and $\mathrm{BC}$, let $y_{1}, y_{2}$ be the recombination values for each segment, $y_{1+2}$ the recombination value for the entire segment $\mathrm{AC}$, and $y_{12}$ the frequency of simultaneous recombination in both segments, then $\mathrm{K}$ is given by--

$$
\frac{y_{12}}{2 y_{1} y_{2} y_{1+2}}
$$

Kosambi (1944) has proposed the relation $2 y=\tanh (2 x)$ to relate the map distance $x$, and the recombination value $y$ between two loci. When $\mathrm{K}=\mathrm{I}$, Kosambi's relation is satisfied. In practice, for 
Drosophila (Owen, I948), and maize (Parsons, I957c), $\mathrm{K}$ is found to exceed unity in the proximal regions of long chromosome arms, and drop below unity in the distal regions. Owen (1948, 1949) has expressed $x$ and $y$ in terms of a metric $u$. in which interference is uniform, and has postulated $f(u)=4 u e^{-2 u}$ in which the intercept length is distributed as $\frac{1}{4} \chi_{4}^{2}$ as an adequate fit to the observed data. Assuming this form for the interference function, $\mathrm{K}=\mathrm{I}$ at the metrical mid-arm of long chromosonies. Calculation of $\mathrm{K}$ values will therefore provide a valuable guide to the nature of interference along the chromosomes. In table $10, \mathrm{~K}$ values are given for the four possible triplets of loci for contiguous segments with their standard errors calculated from the formula given by Owen $(1953 b)$.

TABLE Io

Kosambi coefficients

(Order $f z-S p-\ln -p y$ )

\begin{tabular}{|c|c|c|}
\hline Triplet & Female & Male \\
\hline & & - \\
\hline$f z-l n-p y$ & $0 \cdot 982 \pm 0 \cdot 046$ & $0.611 \pm 0 \cdot 051$ \\
$f z-S p-p y$ & $0 \cdot 976 \pm 0 \cdot 046$ & $0 \cdot 620 \pm 0.051$ \\
$f z-S p-l n$ & $0.694 \pm 0 \cdot 105$ & $0.782 \pm 0.156$ \\
$S p-l n-p y$ & $0.862 \pm 0 \cdot 124$ & $0 \cdot 743 \pm 0 \cdot 211$ \\
\hline
\end{tabular}

There is a major sex difference reflecting that of the recombination values. In the male data $\mathrm{K}$ values are consistently lower than those for the female data. The data from female heterozygotes, with the exception of $f z-S p$ - $l n$, give $\mathrm{K}$ values not significantly lower than unity, whereas all values for the male data are well below unity. The $\mathrm{K}$ values for $f z-\ln -p y$ and $f z-S p-p y$ are based on a large number of double recombinants and are consequently more accurate than $K$ values based on triplets which include the short segment $S p$-ln. $S p$ misclassification, if present, would give spuriously high $\mathrm{K}$ values due to the increase of the double recombinant class by misclassification of single or non-recombinants as double recombinants. In these data, triplets with $S p$ included do not give higher values, an observation which suggests that $S p$ misclassification is negligible.

Taking the male data by itself, all $\mathrm{K}$ values are below unity. On existing data, in organisms other than mice, this observation is indicative of a centromere situated outside the segment under discussion or close to one of its ends but just within it. Further investigation of the male data does not allow a decision to be made as to which end may be involved. In the female data, all $\mathrm{K}$ values are close to unity except for the segment $f z-S p$ - ln for which $\mathrm{K}=0 \cdot 694 \pm 0 \cdot 105$. As $\mathrm{K}$ values are expected to decrease with distance from the centromere, it scems probable that the centromere is near to $p y$ rather than near to $f z$, and in view of the low $\mathrm{K}$ values for the male data, the centroniere is probably outside the whole segment. 
The data, however, scarcely in this case afford a decision for it is possible that interference could be generally more intense in mice than in other organisms studied so far. This is supported by Owen's (I 953) data and Wallace's ( I957) data for linkage group V.

Additional evidence can be drawn from the sex differences in recombination. Changing the interference metric will result in a variation of the recombination fraction between loci, the greatest variation occurring in the centromeric regions where the metric is most sensitive to change. If the sex differences can be explained as due to a different metric for each sex, there would be a large sex difference in recombination near the centromere decreasing with distance from the centromere. In the data under analysis, the greatest sex difference is for the segment $p y-l n$. Hence, on this hypothesis, it can be said that the centromere must be located near $p y$ which is in agreement with the interference data.

Further evidence on the sensitivity of centromeric regions to changes of metric comes from studies on the effect of environmental and genetic variables on recombination, if again it is assumed that such variables operate by varying the metric. Temperature (Plough, I917), age (Bridges, I9I5), X-rays (Muller, I925), and heterozygous inversions (Schultz and Redfield, I95I) have been shown to produce a variation in recombination near the centromere but very little elsewhere.

\subsection{Mapping the chromosome}

Using Owen's $\frac{1}{4} \chi_{4}^{2}$ distribution for the interference function, Fisher (I95I) expressed the frequencies of all recombination classes for any number of linked loci on a finite arm in terms of a combinatorial scheme based on four simple functions $\alpha, \beta, \gamma$ and $\delta$ which he termed segmental functions and are tabulated in Fisher and Yates ( 1953$)$.

Segments are assigned various metrical lengths and from these, expected recombination values can be found using segmental functions, and then compared with observed with a $\chi^{2}$ te $\operatorname{sic} \therefore$ the best fitting metrical lengths, the values of the map distance $x$ between two loci may be calculated using the formula

$$
x_{12}=\left[u \tanh 2 \mathrm{~T}+\frac{\cosh 2(\mathrm{~T}-2 u)-\cosh 2 \mathrm{~T}}{4 \cosh 2 \mathrm{~T}}\right] \begin{aligned}
& t_{2} \\
& t_{1}
\end{aligned}
$$

where $\mathrm{T}$ is the metrical length from centromere to terminus, and $t_{2}$ and $t_{1}$ are the metrical distances of the two loci from the centromere such that $t_{2}>t_{1}$ (Owen, I943).

For the data from the inale heterozygotes, the following map was

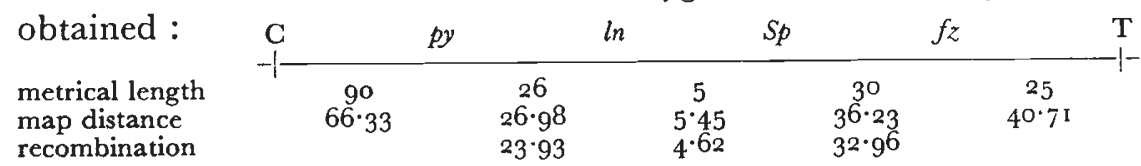
where $\mathrm{C}$ represents the centromere, and $\mathrm{T}$ the terminus. This map 
gave $\chi_{6}^{2}=6.43(0.3<\mathrm{P}<0.5)$ for a goodness of fit test. The arm is I $75.70 \mathrm{cM}$ long, approximately one-third of this distance being from the centromere to $p y$. This long proximal segment is reflected in the low $\mathrm{K}$ values obtained from the male data. Furthermore, the map distances between the markers $p y, \ln , S p$ and $f z$ are close to the observed recombination values, as at this distance the effect of the centromere is lost.

For the female data, the following map was obtained :

metrical length map distance recombination

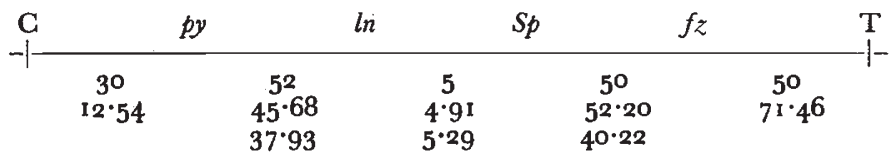

This map gave $\chi_{7}^{2}=22.62 \quad(\mathrm{P}<\mathrm{O} \cdot \mathrm{OI})$ for goodness of fit, which is clearly highly significant. In this case the total length of the arm is $186.79 \mathrm{cM}$ which is only $10.09 \mathrm{cM}$ longer than the map for male data. However, the $\mathrm{K}$ values for females are higher, and the $\mathrm{C}-p y$ segment much shorter than for the males. Assuming the $\frac{1}{4} \chi_{4}^{2}$ metric of intercept length, a recombination value of $52 \cdot 48$ per cent. is expected between $p y$ and $f z$ whereas the observed value was 49.32 per cent. The observed value is significantly different from the expected value $\left(\chi_{\mathrm{r}}^{2}=5.38, \mathrm{P}<0 \cdot 05\right)$. This large discrepancy therefore accounts for the poor fit of the map obtained using segmental functions.

The female data are therefore of theoretical importance in determining when recombination can be expected to be $>5^{\circ}$ per cent. Recombination values of more than 50 per cent. have been reported in mice for the factors dilute and wavy (Fisher and Mather, I936a, I $936 b$ ), and for sex with both shaker and wavy (Wright $=$ Wallace, I947). Other cases reported are those of Wellensiek (1929) in Pisum and Clausen (1926) in Viola.

In the absence of interference, $y$ is always less than 50 per cent. and increases towards 50 per cent. as a limit. If interference were complete, then $x=y$, and the increase in $y$ would keep pace with that in $x$. Observation suggests that interference is always incomplete and vanishes over long intervals, so that on a long chromosome two loci remote from each other would exhibit extremely loose linkage and would segregate showing recombination of 50 per cent. with one another. This leaves the question of less remote loci which may show recombination greater than $5^{\circ}$ per cent. as in fact has occurred, and is predicted by the $\frac{1}{4} \chi_{4}^{2}$ metric. Data for segments likely to show recombination greater than $5^{0}$ per cent. are therefore of extreme value in determining whether the $\frac{1}{4} \chi_{4}^{2}$ metric is realistic, or whether some small alteration is needed in the metric. For this reason, this experiment was set up, and the result shows that the $\frac{1}{4} \chi_{4}^{2}$ metric may need some small adjustment, although it must be pointed out that for shorter segments this metric has been shown to be a good approximation in mice, maize, and Drosophila. 
In mice, Wallace (1947) reported a case of recombination significantly in excess of 50 per cent., a phenomenon Owen (i $953 a$ ) has termed super-recombination. The two factors $w v_{2}$ (wavy-2) and $s h_{2}$ (shaker-2) showed respectively with sex 56.07 and 56.73 per cent. recombination and $3 \mathbf{I} \cdot 06$ per cent. recombination with each other. Fisher, Lyon and Owen (1947) showed that these results could be accounted for on the basis of genetical interference and this was extended by Owen (1953a) to take into account chromosones of finite lengths. In this discussion Owen shows that the delicate phenomenon of super-recombination shows up the slight quantitative differences between the distribution proposed by Fisher, Lyon and Owen (1947) :

$$
\frac{d}{d u}\left(-\operatorname{sech} \frac{\pi \mu}{2}\right)
$$

and the more convenient mimic $4 u e^{-2 u}$ which is distributed as $\frac{1}{4} \chi_{4}^{2}$. The data presented here for linkage group XIII fall into the small group of data which could possibly give information on superrecombination and hence test any proposed metric. That no superrecombination occurs is significant, and shows that the $\frac{1}{4} \chi_{4}^{2}$ distribution of intercept lengths is not adequate in this case.

As well as this difficulty in the female data a striking sex difference in recombination is demonstrated which indicates that each sex for linkage group XIII requires a specific but different distribution of intercept lengths in terms of which interference is uniform. This is supported by Wallace's (1957) data for linkage group V as well as a general tendency in the house mouse for recombination values to be greater in the female.

\section{SUMMARY}

1. Linkage data for the four genes $f z-S p$-ln-py in the house mouse are presented for male and female quadruply heterozygous parents.

2. The data are balanced, each possible quadruple heterozygote having been made up.

3. Several preliminary tests are carried out to detect viability and manifestation disturbance and the results of these tests are taken into account when the recombination values are computed.

4. A large sex difference in recombination was found, the male values being lower than the females except for the entire segment $p y-f z$.

5. The sex difference in recombination was reflected in a major sex difference in interference. The male interference data are incompatible with the centromere within the segment $p y-f z$.

6. The chromosome is mapped using the segmental functions tabulated in Fisher and Yates ( I 953) for the $\frac{1}{4} \chi_{4}^{2}$ distribution of intercept lengths proposed by Owen. A good fit was obtained for the data from male heterozygotes but data from the female heterozygotes gave a 
bad fit. On theoretical grounds the female data should have given a $p y-f z$ recombination of $52 \cdot 4^{8}$ per cent. thus exhibiting super-recombination, but the observed value was 49.32 per cent. The possibility that the $\frac{1}{4} \chi_{4}^{2}$ distribution may not be quite adequate is suggested and also the possibility of different distributions of intercept length for each sex.

Acknowledgment.-I am indebted to Professor Sir Ronald Fisher, F.R.s., for making his records available to me, and for his encouragement and helpful discussion throughout the course of this work.

\section{REFERENCES}

BRIDGeS, C. B. 1915. A linkage variation in Drosophila. 7. Exp. Zool., 19, I-21. CLAusen, J. 1926. Genetical and cytological investigations on Viola tricolor and $V$. arvensis. Hereditas, $8,1-156$.

Dickie, M. M., AND woolley, G. W. 1950. Fuzzy mice. J. Hered., 4I, 193-196. ENGEL, R. J. 1956. A description of polydactylism in mice. F. Hered., 47, 181-187. FISHER, R. A. I928. The possible modification of the response of the wild type to recurrent mutations. Amer. Nat., 62, i I 5-1 26.

FISHER, R. A. 1949. Note on the test of significance for differential viability in frequency data from a complete three-point test. Heredity, 3, 215-219.

Fisher, R. A. 1950. Polydactyly in mice. Nature, ${ }_{1} 65,407$.

FISHER, R. A. 195I. A combinatorial formulation of multiple linkage tests. Nature, $I 67,520$.

Fisher, R. A. 1953. The linkage of polydactyly with leaden in the house mouse. Heredity, 7, $91-95$.

Fisher, R. A., LYON, M. F., AND OWEN, A. R. G. 1947. The sex chromosome in the house mouse. Heredity, $I, 355-365$.

FISHER, R. A., AND MATHER, K. I936a. Verification in mice of the possibility of more than $5^{\circ}$ per cent. recombination. Nature, ${ }_{137,562 .}$

Fisher, R. A., AND Mather, K. r936b. A linkage test with mice. Ann. Eug., 7, 265-280.

Fisher, R. A., AND yates, F. 1953. Statistical Tables for Biological, Agricultural and Medical Research. $4^{\text {th }}$ edition. Oliver and Boyd, Edinburgh.

FORTUYN, A. B. D. 1939. A polydactylous strain of mice. Genetica, 21, 97-108.

HOLT, S. в. 1945. A polydactyl gene in mice capable of nearly regular manifestation. Ann. Eug., 12, 220-249.

HOLT, S. B., AND WRIGHT, M. E. (= WALLACE). 1946. A further note on polydactyly in mice. Ann. Eug., 13, 206-207.

KosAmbi, D. D. 1944. The estimation of map distances from recombination values. Ann. Eug., I2, I 72-I 75 .

MULLER, H. J. 1925. The regionally differential effect of X-ray's on crossing-over in the autosomes of Drosophila. Genetics, 10, 470-507.

murray, J. M. 1932. Polydactylism in mice. Science, 715, 312.

MURRAY, J. M. 1933. Polydactylism in mice. Anat. Rec., 57, 63 (Abstr.).

owen, A. R. G. 1948. Ph.D. Dissertation, University Library, Cambridge.

OWEN, A. R. G. I949. The theory of genetical recombination. I. Long chromosome arms. P.R.S., B, $136,67-94$.

OWEN, A. R. G. 1950. The theory of genetical recombination. Advances in Genetics, 3 , II 7-157.

OWEN, A. R. G. 1953a. Super-recombination in the sex chromosome of the mouse. Heredity, 7, 103-1 10.

OWEN, A. R. G. 1953b. The analysis of multiple linkage data. Heredity, 7, 247-264. 
PARSONS, P. A. I957a. An effect of gene arrangement on recombination in Drosophila. Heredity, II, II 7-I 27.

PARsons, P. A. I $957 b$. Partial manifestation of a gene in complete three and higher point backcross data. Heredity, II, 2 I 7-222.

PARsons, P. A. 1957c. Genetical interference in maize. Nature, 179, 161-162.

PLOUgh, н. H. 1917. The effect of temperature on crossing-over in Drosophila. F. Exp. Zool., 24, 147-209.

RUSSELL, W. L. 1947. Splotch, a new mutation in the house mouse, Mus musculus. Genetics, 32, 102.

SCHULTZ, J., AND REDFIELD, H. I951. Interchromosomal effect on crossing-over in Drosophila. Cold Spring Harbor Symposia on Quantitative Biology, 16, 175-197.

SNELL. G. D., DICKIE, M. M., SMITH, P., AND KELTON, D. E. I954. Linkage of looptail, leaden, splotch and fuzzy in the mouse. Heredity, 8, 271-273.

strong, t. C. I934. Two new structural characters in mice. Anat. Rec., 58, 88 (Abstr.)

STRONG. L. C., AND hOllander, W. F. 1949. Hereditary looptail in the house mouse. J. Hered., 4o, 329-334.

WALLACE, M. E. I 947 . Two sex linkages in the house mouse with unusual recombination values. Heredity, $I, 349-354$.

WALLACE, M. E. I957. A balanced three-point experiment for linkage group V of the house mouse. Heredity, $I I, 223-258$.

WELLENSIEK, S. J. 1929. The occurrence of more than 50 per cent. crossing-over in Pisum. Genetica, 11, 509-518. 